\title{
Selective language deterioration in chronic schizophrenia
}

\author{
R SILVERBERG-SHALEV,* H W GORDON, $\dagger$ S BENTIN, * \\ A N D A ARANSON \\ From the Aranne Laboratory for Human Psychophysiology and Neurobehavioral Studies, \\ Department of Neurology, Hadassah University Hospital and Bikur Holim Hospital,* Jerusalem, \\ Western Psychiatric Institute and Clinic, University of Pittsburgh, $\dagger$ and the Talbieh Mental Hospital, \\ Jerusalem, Israel
}

SUMMARY Chronic schizophrenics as a group were inferior to controls on tests of neuropsychological function. When divided into groups according to length of illness they differed from each other primarily in tests of language. No other deficits in cognitive function progressed; the performance of the patients on memory, visuo-spatial tasks, rate of information processing and abstract thinking did not decline according to length of illness. The results indicate that chronic schizophrenia is characterised by a selective deterioration of language, which correlates with the notion that schizophrenia may be associated with left hemisphere dysfunction.

Chronic schizophrenia has been associated with cognitive abnormality in addition to behavioural and thought disorder. ${ }^{1}$ However, the specific cognitive deficits proposed have been many and varied, contradictory reports abound and little agreement can be found as to the nature of the intellectual impairment. Verbal functions usually are considered preserved relative to those of performance, ${ }^{2}$ but the reverse has also been reported. ${ }^{3}$ Other deficits attributed to the schizophrenic disorder are reduced attention span, ${ }^{45}$ inability to learn new material, ${ }^{67}$ and a decreased rate of information processing. ${ }^{8}$ It has been proposed that in aged schizophrenic patients, dementia is a function of the natural degenerative process of ageing and not related at all to the disease process of schizophrenia itself. ${ }^{918}$ It has also been suggested that mental deterioration is secondary to the effect of chronic hospitalisation, ${ }^{11}$ and that intellectual deficits remain stable and may even improve with time. ${ }^{1213}$ These contradictory reports are at least in part, owing to the differing conditions under which the siudies were performed. Some of them were performed on schizophrenic patients during acute attacks of the disease; while others were on chronic schizophrenics

Address for reprint requests: Dr Ruth S Shalev, Aranne Laboratory for Psychophysiology, Hadassah University Hospital, P.O. Box 12000, Jerusalem, Israel.

Accepted 23 March 1981 hospitalised for prolonged periods. Still others were conducted only on elderly schizophrenic patients. We have attempted to reassess the question of mental deterioration in chronic schizophrenia to bypass the problems of acute changes. An outpatient population, the majority under the age of 50 years, were chosen to avoid problems of senescence and chronic hospitalisation. We administered a rigorous battery of neuropsychological tests of language, memory, abstract thinking, rate of information processing and visuospatial functions. These tests were given to groups of chronic schizophrenic patients, differing from each other in the length of their illness. If mental deterioration is part of the symptomatology of chronic schizophrenia, a changing pattern of cognitive performance should occur.

\section{Patients}

Eighty-eight patients were drawn from four outpatient psychiatric clinics after reviewing their records. Only those with a definite diagnosis of schizophrenia confirmed by at least two psychiatrists and made during a previous hospitalisation in a psychiatric department, were included in the study. Eleven of the 88 were excluded from the final analysis either because they refused to complete the battery or because they had no formal education. The remaining 77 had all received major tranquillisers at some time during their illness and $57(76.6 \%)$ were receiv- 
ing them at the time of testing. Five $(6.5 \%)$ had received electroconvulsive therapy, two $(2.5 \%)$ insulin shock therapy and none had undergone frontal lobectomy.

The patients were divided into three groups according to the length of illness from time of diagnosis: Group I-1-7 years; Group II-8-15 years; Group III $->15$ years. Data on the patient's age, sex, education and drug history at time of testing are shown in table 1. A control group was drawn from patients hospitalised in a general hospital for illnesses other than psychiatric or neurological. Informed consent was obtained from all tested.

Table 1 Subject population data

\begin{tabular}{|c|c|c|c|}
\hline Schizophrenic subjects & $\begin{array}{l}\text { Group I } \\
\text { (I-7 years) }\end{array}$ & $\begin{array}{l}\text { Group II } \\
(8-15 \text { years })\end{array}$ & $\begin{array}{l}\text { Group III } \\
(16-23 \text { years })\end{array}$ \\
\hline Number of Ss & 16 & 32 & 29 \\
\hline Mean age at testing & 27 & 31 & 45 \\
\hline Age range & $21-38$ & 24-43 & $32-61^{*}$ \\
\hline $\begin{array}{l}\text { Years of education } \\
\text { (mean) }\end{array}$ & 10 & 10 & 8 \\
\hline $\begin{array}{l}\text { Number of Ss on drugs } \\
\text { at time of testing }\end{array}$ & 12 & 23 & 22 \\
\hline Control Subjects & Group I & Group II & \\
\hline Number of Ss & & & \\
\hline Mean age at testing & & & \\
\hline A ge range & $21-38$ & $39-69$ & \\
\hline $\begin{array}{l}\text { Years of education } \\
\text { (mean) }\end{array}$ & 10 & 10 & \\
\hline
\end{tabular}

*There were 6 subjects older than age 50 .

\section{Methods}

A neuropsychological battery tested specific cognitive functions. It was presented to each subject individually over two 25 minute sessions on separate days and included tests of language, visuo-spatial perception, memory, abstract thinking and rate of information processing. For details of this test, see Appendix 1. The test was administered in a quiet room of the psychiatric clinic following the patient's regular visit to his physician. Only the examiner and subject were present during the test. Controls were tested in a single session during a brief hospitalisation for nonneurological, non-psychiatric illnesses.

\section{Results}

Schizophrenic patients, as a group, were inferior to the controls on virtually all 42 tests administered, but these differences were statistically significant for only seven tests, six of which were of language (differences among groups were determined by a one-way ANOVA) (table 2). Post-hoc $t$ tests showed that the differences occurred only between Group III and Group II; no differences were found between Group I and Group II. Performances by
Table 2 Means, $F$ and $P$ values of subtest ${ }^{*}$ in which Group III schizophrenics performed significantly differently from Group II patients

\begin{tabular}{llll}
\hline Test & Means & $F$ & $P(<)$ \\
\cline { 2 - 3 } & Group & Group & \\
II & III & \\
\hline
\end{tabular}

\section{Language tests}

Body part namin

Confrontation naming

Animal naming

Letter naming

Complex ideational material

Body-part identification

Visuo-spatial test

Visual organization

\begin{tabular}{rrrr}
$77.8 \dagger$ & $67.2 \dagger$ & 4.22 & 0.02 \\
$60.9 \dagger$ & $44.5 \dagger$ & 7.04 & 0.01 \\
$12.0 \ddagger$ & $9.9 \ddagger$ & 5.15 & 0.01 \\
$8.0 \ddagger$ & $5.0 \ddagger$ & 6.19 & 0.01 \\
$46.0 \dagger$ & $30.0 \dagger$ & 3.56 & 0.05 \\
$79.0 \dagger$ & $68.0 \dagger$ & 6.77 & 0.01 \\
& & 5.67 & 0.005 \\
\hline
\end{tabular}

* In all the other subtests $\mathrm{p}>0.05$.

$\dagger \%$ of correct answers.

¥ Absolute number of words produced

Group III were consistently inferior to their agematched controls, so the schizophrenic patients had an overall deficit of function not related to their age. However, the chronicity of the disease had a specific effect on language.

The most affected language tests were conírontation naming and body part naming, followed by the word productions tests of fluency and category naming. In confrontation, Group III could only name about $45 \%$ of the items compared with $60 \%$ for Group II and $60 \%$ for Group I. Word production was also low where controls achieved nine words per minute; Group III only produced four; Group II, six to seven and Group I, eight. The naming errors of the schizophrenic patients were primarily anomic with an occasional verbal paraphasic error, generally related by category to the word in question, for example, horse instead of unicorn. Phonemic paraphasic errors, neologisms or other bizzare words were not elicited.

While there was a decline in comprehension of complex ideational material (sentences), comprehension of simple commands, writing, and repetition of automised sequences were not affected. The one non-language test that showed significant deterioration in Group III, visual organisation, required recognition of dismembered pictures of common objects and identification by verbal report. In the light of the deficiencies on the naming tests, it was not clear whether the deficit here was due to the inability to organise the pieces of the picture into a whole or to name it. There were no differences among the groups for right-left orientation, house assembly and facial recognition, the other visuo-spatial tests.

Immediate memory (digit span) was virtually 
the same for each of the three groups as was learning of word sequences in supra span. No differences in performance were seen in two high performance, timed tests: the paced sequential addition tests and the trail making test. Group III was able to add successively presented digits at all rates with just as few errors as Group II, and Group II performed as well as Group I on this test. Similarly, Group III did not take longer than Group II, and Group II than Group I in the Parts A or B of trail making. These results reinforce the idea that progressive decline in cognitive function is specific to language processes, particularly in oral production.

In a separate analysis, the schizophrenic groups were joined together and then divided according to presence or absence of paranoia and compared on all tests. There were no differences on any of the tests with two exceptions, confrontation naming $(t=-2 \cdot 18, \mathrm{p}<0.05)$ and supra $\operatorname{span}(t=1.97$, $\mathrm{p}>0.5$ ), where the paranoid patients performed better than those without paranoia in the first and the non paranoid patients tetter in the second.

\section{Discussion}

The results indicate that progressive cognitive dysfunction in the area of language is part of the symptom complex of chronic schizophrenia. Since no other functions were affected, including tests of memory, attention and rate of processing, the deterioration process is quite selective and not a general decline in cerebral functions. While disorders of language are not uncommon in schizophrenia, their relationship to aphasia is not clear. Characteristics of schizophrenic language, such as associative loosening, tangentiality and illogicality are uncommon in aphasia whereas comprehension of spoken language, spontaneous speech, repetition and reading, characteristically impaired in aphasia, may be intact. However, there appears to be a subgroup of schizophrenic patients with disorders of language in whom aphasic deficits of anomia, paraphasia and neologisms appear during the progress of the disease. ${ }^{14}$ Our patient population seems to belong to such a subgroup of schizophrenic patients.

It seems unlikely that the language defects were due to the ageing process rather than the schizophrenia itself. Language functions are generally preserved in the elderly and do not deteriorate with time. ${ }^{15} 16$ Moreover, the mean age of the oldest group of schizophrenic patients was 45 years, the eldest being only 61 years old. When this group was compared to the older control group, whose mean age was 53 (range 36-69), the performance of the controls was still found to be superior. One source of cognitive decline reported for schizophrenic patients has been the factor of hospitalisation. ${ }^{13}$ This factor was avoided in our results since all patients were ambulatory and hospitalised only during acute relapses. It is concluded that the present results reflect effects of the disorder.

The present results indicate that chronic schizophrenia is characterised by a selective deterioration of cognitive functions in the area of language, indicative of left hemisphere dysfunction. The findings correlate with the notion that schizophrenia is associated with left hemisphere dysfunction as determined by left temporal abnormalities seen in power-spectra electroencephalograms, ${ }^{17}$ more left-sidedness in measures of handedness, footedness and eyedness, ${ }^{18}$ and on verbal tests. ${ }^{19}$ It is not clear, however, that there is a general left hemisphere deficit since many of the tests showing no progressive decline could also be attributed to the left hemisphere. On the other hand, all test performances were deficient relative to controls showing some general lowering of performance with a progression only in the area of language.

We thank Dr Eisenberg of the Ruth Mental Health Clinic, Talbieh Hospital, Ezrat Nashim Outpatient Clinic, Kiryat Yovel Mental Health Clinic and the Community Mental Health Center for their co-operation, advice and referral of patients. We also thank Ms Gaila Obstfeld for her help in patient testing.

This study was supported by a grant from the Charles E Smith Foundation, The Israel Center for Psychobiology.

\section{References}

1 Bluer E. Dementia Praecox or the Groups of Schizophrenias. Leipzig: IVP, 1911 (New York 1950).

2 Lubin A, Gieseking CF, Williams HL. Direct measurement of cognitive deficit in schizophrenia. $J$ Consulting Psychol 1962; 26:139-43.

3 Engel NS. Intellectual performance of young schizophrenic males. S Afr Med J 1973; 49: 2129-30.

4 Shakow D. Segmental set: a theory of the formal p3ychological deficit in schizophrenia. Arch Gen Psych 1967; 6:1-17.

5 Blum RA. Changes in cognition, attention and language in acute schizophrenia. Dis Nerv Sys 1969; 30:31-6. 
6 Hall KRL, Crookes TG. Studies in learning impairment. I. Schizophrenic and organic patients. J Ment Sci 1951; 97:725-37.

7 Galdis M. Retention of verbal paired associates by schizophrenic subjects. Psychol Reports 1967; 21: 241-6.

8 Marshall WL. Cognitive functioning in schizophrenia. Br J Psychol 1973; 123:413-33.

9 Muller C. Schizophrenia in advanced senescence. Bri J Psychiatry 1971; 118:347-8.

10 Lerner J, Lerner WD. Aging process in schizophrenia. Md State Med J 1973; 22:74-6.

11 Hamilton V. IQ changes in chronic schizophrenia. Br J Psychiatry 1963; 103:642-8.

12 Smith A. Mental deterioration in chronic schizophrenia. J Nerv Ment Dis 1964; 139:479-89.

13 Hamlin R. The stability of intellectual function in chronic schizophrenia. J Nerv Ment Dis 1969; 149:496-503.

14 Andreasen NC. Grove W. The relationship between schizophrenic language, manic language and aphasia. In: Gruzelier J, Flor-Henry P, eds. Hemisphere Asymmetries in Function Psychopathology. Amsterdam: Elsevier/North Holland 1979.

15 Wang HS. Dementia of old age. In: Smith LW, Kinsbourne M, eds. Ageing and Dementia. New York: Spectrum Publication 1977.

16 Kinsbourne $M$. Cognitive decline with advancing age: an interpretation. In: Smith LW, Kinsbourne M, eds. Ageing and Dementia. New York: Spectrum Publication 1977.

17 Flor-Henry P. Lateralized temporal-limbic dysfunction and psychopathology. Ann NY Acad Sci 1976; 280:777-97.

18 Gur RE. Left hemisphere dysfunction and left hemisphere overactivation in schizophrenia. $J$ Abnormal Psychol 1978; 87:226-38.

19 Davison K, Bagley CR. Schizophrenic-like psychoses associated with organic disorders of the central nervous system. A review of the literature. In: Herrington RN, ed. Current Problems of Neuropsychiatry. Royal Medicopsychological Assn, Ashford, Kent, England: Headley Bros. 1969.

20 Goodglass H, Kaplan E. The Assessment of Aphasia and Related Disorders. Philadelphia: Lea and Febiger 1972.

21 Benton AL, de S Hamsher K. Multilingual Aphasia Examination. Iowa City, Iowa: Department of Neurology, University Hospitals 1976.

22 Albert ML. A simple test of visual neglect. Neurology (Minneap) 1973; 23:658-64.

23 Benton AL, Van Allen MW, de S Hamsher K, Levin HS. Test of Facial Recognition, Form SL. Iowa City, Iowa: Department of Neurology, University of Iowa 1975.

24 Grunwell D, Wrightson P. Delayed recovery of intellectual function after minor head injury. Lancet 1974; 1:605-9.

\section{Appendix}

Testing procedure-neurophysiological battery

I Language tests (1-3, 5-11 were adapted from the Boston Diagnostic Aphasia Examination). 20

(1) Body-part naming: the subject was asked to name nine different body parts indicated by the examiner.

(2) Visual confrontation naming: the subject was to name 24 items each drawn on an individual card and shown to the subject.

(3) Category naming (animals): the subject was to list orally as many animals as he could for 90 seconds. He was scored on the best consecutive 45 seconds.

(4) Fluency ${ }^{21}$ : the subject was to list orally as many words as he could for three different letters in the alphabet. He was allowed 90 seconds for each letter and was scored on the best consecutive 45 seconds.

(5) Commands: the subject was to carry out four different commands such as "put the pencil on top of the card, then put it back."

(6) Complex ideational material: the subject was to respond to six different questions such as: "Will a board sink in water?"

(7) Oral agility: the subject was carry out as rapidly as possible repeated mouth movements such as "pursing the lips" and words such as "tip-top."

(8) Automatised sequences: the subject was to recite the months of the year forwards and backwards. The test was timed.

(9) Spelling: the subject was to identify orally four words spelled aloud.

(10) Written confrontation: the subject was to write out the names of six pictured items.

(11) Written formulation: the subject was shown a picture in which a child was falling off a stool while taking cookies from a jar and his mother, also in the kitchen, was washing dishes at a sink overflowing with water. The subject was to write a description of the picture in as much detail as possible.

II Visuo-spatial perception tasks

(1) Test of visual neglect: ${ }^{22}$ the subject was shown a sheet of paper on which $492 \mathrm{~cm}$ lines arranged in seven rows appeared to be randomly disposed. The task was to cross out all the lines on the sheet.

(2) Right-left orientation: the subject was asked to indicate various body parts with the ipsilateral or contralateral hand.

(3) Visual organisation test: the subject was shown pictures of common objects which had been dismembered and asked to identify the objects. Ten such pictures were shown.

(4) Benton's facial recognition test: ${ }^{23}$ the subject was shown a face and then asked to identify it from a group of similar profiles.

(5) Three-dimensional house: the subject was shown 
a 3-D house and asked to copy it, line by line.

III Memory tests

(1) Immediate memory was tested by a string of digits of four, five and six numbers. Immediately after presentation, the subject was to repeat the digits in the same order as the presentation.

(2) Recent memory or ability to learn new materials was evaluated by two nine-item supra-span tasks, one of which was an associated word list and the other a random word list.

(3) Remote memory was evaluated by five questions on well-known historical events such as: "Who was the first President of the State of Israel?"

\section{Rate of information processing}

The paced auditory serial addition tests ${ }^{24}$ were composed of three trials of fourteen digits each, recorded at intervals of $2.5 \mathrm{~s}$ in the first trial, $2.0 \mathrm{~s}$ in the second trial and $1.5 \mathrm{~s}$ in the third trial. Subjects were told that they would hear a list of numbers, one after the other. They were instructed to add the numbers serially, that is the first to the second, the third to the sum of the first two and so on. Practice trials were given until it was clear that the subject understood the task.

\section{Abstraction}

Trail-making test: the subject was presented with a sheet of paper on which were scattered the numbers 1-10 and the first 10 letters of the alphabet. The subject was required to connect the numeral one to the first letter of the alphabet. He was to continue connecting the numbers to the letters in alternating ascending order until he reached 10 . This was a timed test. 